\title{
Determination of Di-n-Butyl Phosphate in Organic Streams of FBTR Mixed Carbide Fuel Reprocessing Solution by Gas Chromatographic Technique
}

\author{
P. Velavendan, S. Ganesh, N. K. Pandey, U. Kamachi Mudali, R. Natarajan
}

Reprocessing Group, Indira Gandhi centre for Atomic Research, Kalpakkam, India.

Email: velp@igcar.gov.in

Received September $20^{\text {th }}, 2011$; revised October $25^{\text {th }}, 2011$; accepted November $16^{\text {th }}, 2011$.

\begin{abstract}
The present work describes the amount of Di-n-butyl phosphate (DBP) produced when PUREX solvent ( $30 \%$ tri-n-butyl phosphate (TBP) mixed with $70 \%$ hydrocarbon diluent) is exposed to intensive radiolytic and chemical attack during the separation of uranium and plutonium from fission products of FBTR mixed carbide fuel reprocessing solution. DBP is the major degradation product of Tri-n-butyl phosphate (TBP). Amount of DBP formed in the lean organic streams of different fuel burn-up FBTR carbide fuel reprocessing solutions were analyzed by Gas Chromatographic technique. The method is based on the preparation of diazo methane and conversion of non-volatile Di-n-butyl phosphate in to volatile and stable derivatives by the action of diazomethane and then determined by Gas Chromatography (GC). A calibration graph was made for DBP over a concentration in the range from 200 to $1800 \mathrm{ppm}$ with correlation coefficient of 0.99587 and RSD 1.2\%. The degraded 30\% TBP-NPH solvent loaded with heavy metal ions like uranium was analyzed after repeated use and results are compared with standard ion chromatographic technique. A column comparison study to select of proper gas chromatographic column for the separation of DBP from other components in a single aliquot of injection is also examined.
\end{abstract}

Keywords: Gas Chromatography, Flame Ionization Detector, Diazomethane, Di-n-Butyl Phosphate, PUREX Process, Degradation of TBP, Lean Organic Streams, Carbide Fuel

\section{Introduction}

Tributylphosphate (TBP) is the most popular reagent in liquid-liquid extraction. Di-n-butyl phosphate (DBP) is one of the degradation products of Tri-n-butyl phosphate (TBP) $\left(\left(\mathrm{C}_{4} \mathrm{H}_{9} \mathrm{O}\right)_{3} \mathrm{P}=\mathrm{O}\right)$, used in the well known PUREX (Plutonium Uranium Refining by Extraction) process [1] for the separation of uranium and plutonium from fission products in nuclear fuel reprocessing. During the solvent extraction process the solvent TBP undergoes degradation by hydrolysis and radiolysis yielding mainly $\mathrm{Di}$ -n-butyl phosphate (DBP) $\left(\left(\mathrm{C}_{4} \mathrm{H}_{9} \mathrm{O}\right)_{2} \mathrm{P}=\mathrm{O}-(\mathrm{OH})\right)$, to a lesser extent monobutylphosphate (MBP) $\left(\left(\mathrm{C}_{4} \mathrm{H}_{9} \mathrm{O}\right) \mathrm{P}=\mathrm{O}\right.$ $\left.(\mathrm{OH})_{2}\right)$, phosphoric acid and butanol [2]. The DBP complexes with $\mathrm{Zr}, \mathrm{Pu}$ and other metal ions [3] which leads to loss of heavy metals to lean organic stream. Hence the quality of PUREX solvent is generally measured in terms of the concentration of DBP. Various analytical methods were reported in the literature for the determination of DBP. Bocek et al. [4] have used high-speed Isotachophoresis, a form of capillary electrophoresis with conductivity detection, to analyze TBP for its degradation products in solutions containing nitrates and nitrites. Muller et al. [5] have determined trace amounts of DBP and TBP in nuclear fuel reprocessing solutions by Liquid Chromatography [6] while Wilkinson and Williams [7] determined DBP and MBP by direct titration of irradiated TBP samples. The latter method fails in presence of nitric acid. Krishnamurthy and Sampathkumar [8] have used titrimetry to determine DBP and MBP as degradation products in the two component TBP-nitric acid system. Grant et al. [9] have performed the separation and measurement of TBP, DBP and MBP by Ion-pair Chromatography with refractive index detection. Infra Red Spectroscopy is used [10] for determination of DBP concentration in the solvent based on the $\mathrm{P}=\mathrm{O}$ absorption at $1230 \mathrm{~cm}^{-1}$ with a poor detection limit due to interferences from the TBP. Techniques [11] of ionization at atmospheric pressure, i.e., electrospray (ESI) or atmospheric pressure chemical ionization (APCI) with Mass Spectrometry (MS) have been used 
for the direct quantification of MBP and DBP in a TBP matrix, without any prior separation. Recently use of ligand-sensitized Fluorescence Spectroscopy [12] is reported for the determination of DBP in $\mathrm{TBP} /$ dodecane solutions with $\mathrm{Tb}^{3+}$ as the fluorescent. This method is suitable for the determination of DBP over the concentration of $0.1 \%-10 \%$ DBP in TBP. Among the various methods of analysis, application of chromatographic methods has gained wider acceptance owing to their high sensitivity and greater resolving power [13] Gas Chromatography (GC) is the most widely used technique for the determination of DBP, mainly in the organic phase. Hardy et al. [14] showed that DBP could be analyzed by gas chromatography of the corresponding methyl esters formed by reaction with diazomethane. Brignocchi et al. [15] developed the gas chromatographic method of Hardy $[16,17]$ into a quantitative procedure for the determination of DBP and MBP in various organic streams $[18,19]$. Experimental details and results obtained by this method are described in this paper

\section{Experimental}

\subsection{Reagents}

Tri-n-butyl phosphate (Merck) and Di-n-butyl phosphate (Fluka). All other chemicals used were of AR or GR grade. Diazomethane was prepared immediately before use from a precursor in the laboratory fume hood and stored in refrigerator. The precursor used in the present study is $\mathrm{N}$-methyl-N-nitroso-p-toluenesulfonamide (Diazald)

\subsection{Instrumentation}

A Shimadzu Gas chromatograph model 14 B equipped with a Flame Ionization Detector (FID) was used to detect the eluted components. Metrhom IC Net 2.3 software is used for data acquisition. A stainless steel column of 4 meters long and 1/8" dia packed with $10 \%$ XE-60 was used for the separation of components. Nitrogen gas with a flow rate of $30 \mathrm{ml} / \mathrm{min}$ was used as carrier gas. Hydrogen gas and zero air with a flow rate of 30 and $300 \mathrm{ml} / \mathrm{min}$ were respectively used to generate flame. Column, Injector and detector temperatures were $230^{\circ} \mathrm{C}, 260^{\circ} \mathrm{C}$ and $260^{\circ} \mathrm{C}$ respectively.

\section{Gas Chromatographic Condition}

Gas chromatograph:

Analytical Column:

Liquid phase:

Nature of the column:

Length:

Diameter:

Solid:

Mesh range:
Shimadzu GC model 14 B

Stainless steel packed column

$10 \%$ XE-60

Polar

4 meters

$1 / 8$ "

Anakrom-ABS

$60 / 80$
Maximum column operating temperature:

Column temperature:

Injector temperature:

Detector temperature:

Fuel gas:

Supporting gas:

Carrier gas:

Carrier gas flow rate:

Hydrogen gas flow rate:

Zero Air flow rate:

Detector:

Detector range:

Detector polarity:

Analytical mode:

Injection volume:

Run time:

Quantitation:

\subsection{Preparation of Diazomethane}

Diazomethane $(\mathrm{CH} 2 \mathrm{~N} 2)$ is the most common methylating reagent for carboxylic acid and has found wide application in the methylation of phenols, enols, and heteroatoms such as nitrogen and sulfur. Diazomethane is easy to prepare and use. It is prepared immediately before use from a precursor, after addition of base. The precursor used in the present study is N-methyl-N-nitroso-p-toluenesulfonamide.

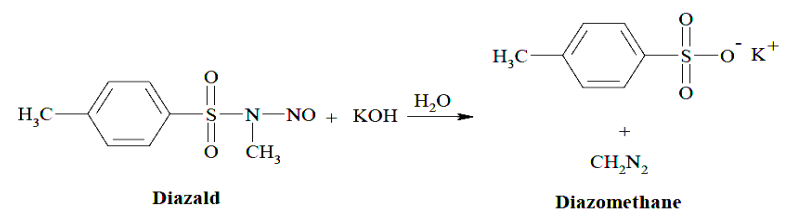

Preparation and handling of diazomethane requires special precautions because it is a highly explosive gas at room temperature. Diazomethane gas may explode violently even if it is diluted with nitrogen (OSHA, US Department of Labor). Contact with sharp or rough surfaces, or heat may cause diazomethane to explode. Diazomethane is a severe pulmonary irritant and causes coughing, fever, fulminating pneumonia, and death on humans. High velocity ventilation in the working area involving diazomethane is needed to guarantee minimum exposure to diazomethane. Diazomethane was prepared by the use of specially designed glassware kit (Aldrich Diazald Apparatus) in order to avoid accidental explosion of $\mathrm{CH} 2 \mathrm{~N} 2$ with sharp or rough surfaces. A safety shield was placed in the highly ventilated reaction hood to provide maximum isolation from exposure to diazomethane and possible explosion. The receiving flask was surrounded by a $\mathrm{NaCl}$-ice bath ( $33 \% \mathrm{NaCl}$ by weight) giving a cool environment at about $-20^{\circ} \mathrm{C}$ because diazomethane is a gas at 
room temperature and liquifies at $-23^{\circ} \mathrm{C}$ (density 1.45 ), and freezes at $-145^{\circ} \mathrm{C}$. Ethanol $(10 \mathrm{ml})$ was added into $\mathrm{KOH}$ solution in the reaction flask, which was prepared by dissolving potassium hydroxide $(5 \mathrm{~g})$ in water $(8 \mathrm{ml})$. The solution of Diazald (5.0 g Diazald in $45 \mathrm{ml}$ ether) was added in the reaction flask, and was heated to $65^{\circ} \mathrm{C}$. The rate of addition of Diazald solution was approximately the rate of distillation. Some extra ether was added in the reaction flask after the Diazald solution was used up in order to trap the entire diazomethane in the receiving flask. The reaction was terminated when the distillate become colorless. The strength of diazomethane was determined Spectrophotometrically at $410 \mathrm{~nm}$ where its extinction coefficient, $\varepsilon$, is 7.2.

\subsection{Procedure}

Stock solution of DBP was prepared in n-dodecane and from this stock solution various concentration of DBP was diluted in n-dodecane and treated with diazomethane solution which was prepared immediately before use from a precursor. Solution was warmed at $60^{\circ} \mathrm{C}$ using a water bath. The ether and the excess diazomethane were evaporated by the flow of nitrogen gas through the solution. After the conversion of DBP into its methyl ester, solution was injected into Gas chromatograph using Hamilton microliter syringe.

$$
\begin{gathered}
\left(\mathrm{C}_{4} \mathrm{H}_{9} \mathrm{O}\right)_{2} \mathrm{POOH}+\mathrm{CH}_{2} \mathrm{~N}_{2} \rightarrow\left(\mathrm{C}_{4} \mathrm{H}_{9} \mathrm{O}\right)_{2} \mathrm{POOCH}_{3}+\mathrm{N}_{2} \uparrow \\
\text { DBP Diazomethane }
\end{gathered}
$$

Radioactive lean organic solutions of various burn-up of FBTR mixed carbide fuel reprocessing solution was washed with $2 \mathrm{~N}$ sulphuric acid to remove any heavy metal ions and then subsequently treated with diazomethane before injection in to Gas chromatograph.

In another experiment degraded solvent of repeatedly used 30\% TBP-NPH phase loaded with $70 \mathrm{~g} / \mathrm{L}$ concentration of uranium was analyzed for its DBP content by this procedure. $3 \mathrm{ml}$ of organic phase was equilibrated twice with $0.01 \mathrm{M}$ nitric acid and subsequently washed twice with $2 \mathrm{~N}$ sulphuric acid to remove heavy metals. Then $0.25 \mathrm{ml}$ of organic phase was taken in a $5 \mathrm{ml}$ standard flask and made up to the mark with n-dodecane. From this $0.2 \mathrm{ml}$ of aliquot was taken in a $15 \mathrm{ml}$ centrifuge tube and followed the above procedure to determine the concentration of DBP.

\subsection{Studies on the Selection of Gas Chromatographic Column for DBP Separation}

Studies were carried out to find best gas chromatographic column for the separation of DBP from hydrocarbon peaks $(\mathrm{C} 10$ to $\mathrm{C} 14)$ and TBP in a single aliquot of inject- tion. Columns of different stationary phases SE-30 and XE-60 were taken for studies. Detailed column parameters were described in Table 1

\section{Results and Discussion}

Diazomethane is an ideal derivatization reagent. The reaction is fast, the yield is high, side reactions are minimal, the by-product is nitrogen gas and reaction conditions are very mild. Diazomethane is a yellow gas so the progress of the reaction can be easily is followed. The reaction for the conversion of DBP to methyl ester is outlined below:
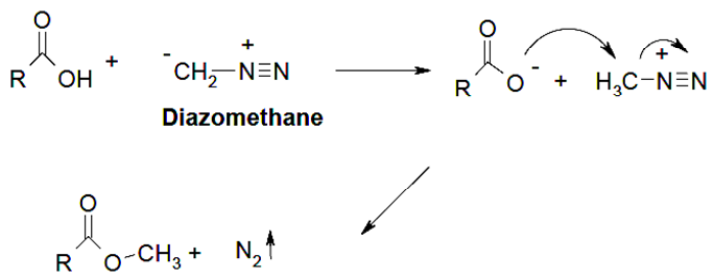

Table 1. Comparison of Column parameters used for the

\begin{tabular}{|c|c|c|}
\hline Properties of Column & XE-60 & SE-30 \\
\hline Material & S.S packed column & S.S packed column \\
\hline Liquid phase & $10 \%$ XE- 60 & $10 \%$ SE-30 \\
\hline Nature & Polar & Non-Polar \\
\hline Length & 4 meters & 4 meters \\
\hline Diameter & $1 / 8^{\prime \prime}$ & $1 / 8 "$ \\
\hline Solid & Anakrom-ABS & $\mathrm{ChW} / \mathrm{HP}$ \\
\hline Mesh range & $60 / 80$ & $60 / 80$ \\
\hline \multicolumn{3}{|l|}{ Maximum } \\
\hline Temperature & $250^{\circ} \mathrm{C}$ & $300^{\circ} \mathrm{C}$ \\
\hline Column temperature & $230^{\circ} \mathrm{C}$ & $230^{\circ} \mathrm{C}$ \\
\hline Injector temperature & $260^{\circ} \mathrm{C}$ & $260^{\circ} \mathrm{C}$ \\
\hline Detector temperature & $260^{\circ} \mathrm{C}$ & $260^{\circ} \mathrm{C}$ \\
\hline Fuel gas & Hydrogen & Hydrogen \\
\hline Supporting gas & Zero air & Zero air \\
\hline Carrier gas & Nitrogen & Nitrogen \\
\hline Carrier Gas flow rate & $30 \mathrm{ml} / \mathrm{min}$ & $30 \mathrm{ml} / \mathrm{min}$ \\
\hline Hydrogen gas flow rate & $30 \mathrm{ml} / \mathrm{min}$ & $30 \mathrm{ml} / \mathrm{min}$ \\
\hline Zero Air flow rate & $300 \mathrm{ml} / \mathrm{min}$ & $300 \mathrm{ml} / \mathrm{min}$ \\
\hline Detector & FID & FID \\
\hline Detector range & 2 & 2 \\
\hline Detector polarity & 1 & 1 \\
\hline Analytical mode & Isothermal & Isothermal \\
\hline Injection volume & $5 \mu \mathrm{L}$ & $5 \mu \mathrm{L}$ \\
\hline Run time & $15 \mathrm{~min}$ & $15 \mathrm{~min}$ \\
\hline Quantitation & Peak area & Peak area \\
\hline
\end{tabular}
separation of DBP from other components. 
Two of the protons in the resulting methyl ester originnate from the diazomethane. The other one is the donated acidic proton from the DBP. A calibration graph (Figure 1) was made for DBP concentration in the range from 200 to $1800 \mathrm{ppm}$ in n-dodecane with correlation coefficient of 0.99587 and RSD $1.2 \%$ and each standard was esterified using diazomethane procedure as described above. By using this calibration graph the concentration of DBP present in the unknown samples were calculated. Table 2 gives results of gas chromatographic determination of DBP and TBP in radioactive lean organic streams of various fuel burn-up of FBTR carbide fuel reprocessing solution. The table confirms that the TBP percentage remains more or close to $30 \%$ and the concentration of DBP is fairly high, its concentration depends on strength of the nitric acid, concentration of plutonium and contact time during the solvent extraction process. The higher DBP concentration in the low burn-up fuel is probably due to delayed stripping of heavy metal ions during the commissioning of the reprocessing plant with low burn-up fuel. Figure 2

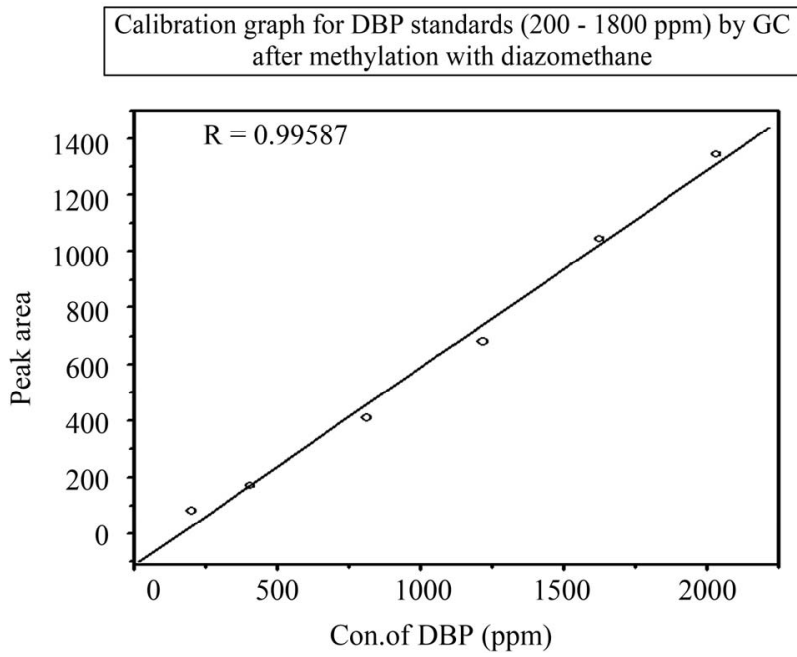

Figure 1. Typical calibration graph for the determination of DBP by gas chromatographic technique after methylation using diazomethane.

Table 2. Results of gas chromatographic determination of DBP and TBP in lean organic streams of various fuel burnup of FBTR mixed carbide fuel reprocessing solution.

\begin{tabular}{ccccc}
\hline S.No & $\begin{array}{c}\text { Fuel Burn-up } \\
(\mathrm{MWd} / \mathrm{T})\end{array}$ & $\begin{array}{c}\text { Nature of the } \\
\text { sample }\end{array}$ & $\begin{array}{c}\text { \% of TBP } \\
\text { determined }\end{array}$ & $\begin{array}{c}\text { Conc. of DBP } \\
(\mathrm{g} / \mathrm{L})\end{array}$ \\
\hline 1 & Low burn-up & Lean Organic & 29.971 & 2.654 \\
2 & $25000-1$ & Lean Organic & 29.508 & 1.664 \\
3 & $25000-2$ & Lean Organic & 29.383 & 2.387 \\
\hline
\end{tabular}

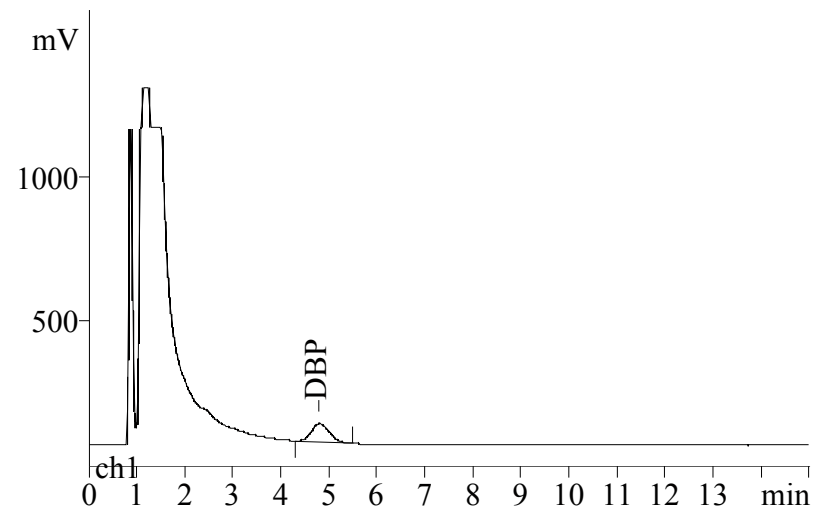

Figure 2. Typical Gas chromatogram of standard Di-nbutyl phosphate (1.659 g/L).

shows the typical gas chromatogram of standard DBP $(1.659 \mathrm{~g} / \mathrm{L})$ after methylation using diazomethane. Figure 3 refers the typical gas chromatogram of DBP and TBP in radioactive lean organic solvent of FBTR carbide fuel (25,000 MWD/T burn-up) reprocessing solution. In Figures 2 and 3 the DBP peak was well separated from hydrocarbon and TBP peaks respectively with the separation factor $(\alpha)$ greater than 1 . Table 3 shows the results of comparison of Gas Chromatographic and Ion chromatographic methods from repeatedly used degraded $30 \%$ TBP-NPH solvent loaded with uranium. Errors estimated in the present gas chromatographic method is about 5\%. All the estimated values of different concentration range of DBP were higher in GC than the estimated values of DBP by IC. This positive error in GC estimation of DBP may be due to pre-concentration of the solution during the conversion of DBP into its methyl ester under hot condition. The peak area obtained was compared with standard calibration graph of DBP obtained by injecting DBP standards every day after methylation using diazomethane. The relative standard deviation was $1.2 \%$ for the repeated nine injections. Table 1 refers the comparison of column parameters used for the separation of DBP from other components. The column selection studies carried out for the separation of DBP is reveal that the best column is XE-60 than SE-30. This is due to the polar nature of column XE-60 separates the non polar hydrocarbon (C-10 to C-14) peaks as a single peak from DBP and TBP (Figure 2 and 3), hence there is no interference of hydrocarbon peak for the separation, identification and quantitative estimation of DBP in the degraded solvent using XE-60. Whereas non polar nature of column SE-30, hydrocarbons $\mathrm{C} 10$ to $\mathrm{C} 14$ (non polar) peaks were individually well separated. It was found that use of column SE-30 the retention time of peak C-14 (tetradecane, retention time $4.5 \mathrm{~min}$ ) and the retention time of DBP peak were same. Therefore SE-30 column is not suitable for the 


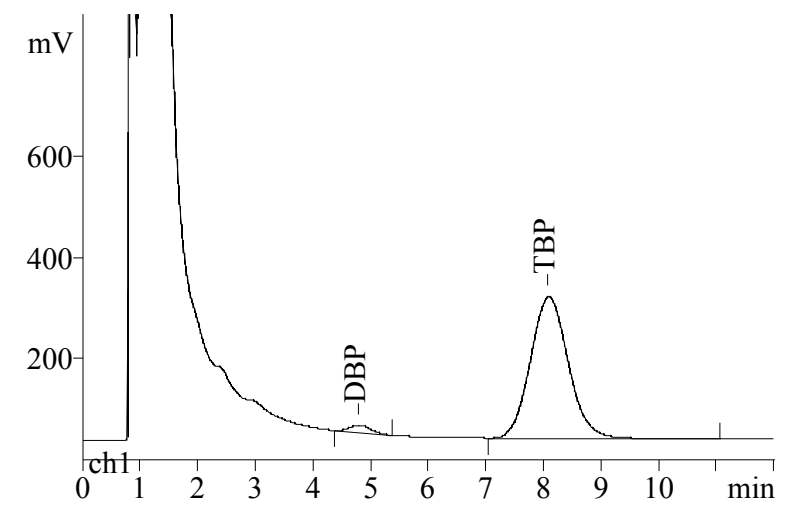

Figure 3. Typical Gas chromatogram of DBP (1.664 g/L) \& TBP $(29.51 \%)$ in lean organic solution of FBTR mixed carbide (25,000 MWD/T Burn-up) reprocessing solution.

Table 3. Estimated values of DBP by present method and Ion chromatographic method.

\begin{tabular}{ccc}
\hline & \multicolumn{2}{c}{ Concentration of $\mathrm{DBP}(\mathrm{g} / \mathrm{L})$ estimated by } \\
\cline { 2 - 3 } Sample no & $\begin{array}{c}\text { Gas chromatography method } \\
\text { (described in this work) }\end{array}$ & $\begin{array}{c}\text { Ion-chromatography } \\
\text { method }\end{array}$ \\
\hline 1 & 14.71 & 14.42 \\
2 & 7.82 & 7.45 \\
3 & 2.63 & 2.41 \\
\hline
\end{tabular}

${ }^{a}$ Errors in the estimates by Gas chromatographic method is about $5 \%$.

qualitative and quantitative estimation of DBP in presence of various hydrocarbons particularly diluent NPH (Normal Paraffin Hydrocarbon) in the degraded solvent of reprocessing plants.

\section{Conclusions}

Analysis of DBP content in the radioactive lean organic streams of FBTR mixed carbide fuel reprocessing solutions by gas chromatography method was demonstrated. It is simple, only needs the conversion of DBP into its methyl ester prior to injection. The major advantage of GC method is the simultaneous determination of MBP, DBP and TBP and hydrocarbons in a single aliquot without any interference using 10\% XE-60 column. The reproducibility and linearity of the method suggest that it is well suitable for the determination of DBP over a concentration in the range from 200 to $1800 \mathrm{ppm}$ and relevant to organic streams of purex process.

\section{Acknowledgements}

Authors wish to express their sincere thanks to Shri S. C. Chetal, Director, IGCAR for motivating them to excel.
The authors are also thankful to Shri. M. Venkataraman, Head, RPOD, for the encouragement provided during the course of this work.

\section{REFERENCES}

[1] W. W. W. Schulz, L. L. Burger and J. D. Navratil, "Science and Technology of Tributylphosphate," Applications of Tributyl Phosphate in Nuclear Fuel Processing, CRC Press, London, Vol. 3, 1990, pp. 267-327.

[2] A. Petru, P. Rajec, R. Cech and J. Kuruc, "Determination of Radiolytic Products of Two-Phase Tributylphos Phate-Water Systems by Capillary Isotachophoresis," Journal of Radioanalytical and Nuclear Chemistry, Vol. 129, No. 2, 1989, pp. 229-232. doi:10.1007/BF02039819

[3] T. Tsujino and I. Ishihara, "Radiation Damage to TBP/Kerosene Solvent, (II)," Journal of Nuclear Science and Technology, Vol. 3, No. 4, 1966, pp. 144-149. doi:10.3327/jnst.3.144

[4] P. Bocek, V. Dolnik, M. Deml and J. Janak, "Separation and Determination of the Degradation Products of Tributyl Phosphate by High-Speed Analytical Isota Chophoresis," Journal of Chromatography A, Vol. 195, No. 2, 1980, pp. 303-305. doi:10.1016/S0021-9673(00)96825-0

[5] M. P. Muller, J. Cojean and A. Deloge, Analyst, Vol. 13, No. 1985 , pp. 160.

[6] R. P. Lash and C. J. Hill, "Ion Chromatographic Determination of Dibutylphosphoric Acid in Nuclear Fuel Reprocessing Streams," Journal of Liquid Chromatography \& Related Technologies, Vol. 2, No. 3, 1979, pp. 417-427. doi:10.1080/01483917908060072

[7] R.W. Wilkinson and T. F. Williams, "801. The Radiolysis of Tri-n-Alkyl Phosphates," Journal of the Chemical Society, 1961, pp. 4098-4107. doi:10.1039/jr9610004098

[8] M. V. Krishnamurthy and R. Sampathkumar, "Radiation-Induced Decomposition of the Tributyl Phosphate-Ni- tric Acid System: Role of Nitric Acid," Journal of Radioanalytical and Nuclear Chemistry, Vol. 166, No. 5, 1992, pp. 421-429. doi:10.1007/BF02167787

[9] K. E. Grant, G. M. Mong, S. A. Clauss, K. L. Wahl and J. A. Campbell, "Determination of Monobutyl Phosphate and Dibutyl Phosphate in Mixed Hazardous Wastes by Ion-Pair Chromatography," Journal of Radioanalytical and Nuclear Chemistry, Vol. 220, No. 1, 1997, pp. 31-35. doi:10.1007/BF02035343

[10] L. Stieglitz, W. Ochsenfeld and H. Schieder, "The Influence of the Radiolysis of Tributyl Phosphate on the Plutonium Yield in the Purex Process for High Plutonium Content," KfK-691, Karlsruhe Nuclear Research Center, 1968.

[11] C. Lamouroux, H. Virelizier, C. Moulin, J. C. Tabet and C. K. Jankowski, "Direct Determination of Dibutyl and Monobutyl Phosphate in a Tributyl Phosphate/Nitric Aqueous-Phase System by Electrospray Mass Spectrometry," Analytical Chemistry, Vol. 72, No. 6, 2000, pp. 1186- 
1191.

doi:10.1021/ac990613y

[12] S. Maji and K. S. Viswanathan, "Ligand-Sensitized Fluorescence of $\mathrm{Tb}^{3+}$ in $\mathrm{Tb}^{3+}$ Dibutylphosphate Complexes: Application for the Estimation of DBP," Spectrochimica Acta, Part A, Vol. 64, 2006, pp. 972-976. doi:10.1016/j.saa.2005.09.006

[13] S. C. Tripathi and P. Bindu, "Studies on the Identification of Harmful Radiolytic Products of 30\% TBP-n-Dodecane- $\mathrm{HNO}_{3}$ by Gas Liquid Chromate Graphy I. Formation of Diluent Degradation Products and Their Role in Plutonium Retention Behaviours," Separation Science and Technology, Vol. 36, No. 7, 2001, pp. 1463-1478. doi:10.1081/SS-100103882

[14] C. J. Hardy, "Analysis of Alkyl Esters of Phosphoricacid by Gas Chromatography," Journal of Chromatography A, Vol. 13, 1964, pp. 372-376. doi:10.1016/S0021-9673(01)95133-7

[15] A. Brignocchi and G. M. Gasparini, "The Gas Chromatographic Determination of the Decomposition Products of Tributyl Phosphate," Analytical Letters, Vol. 6, No. 6, 1973, pp. 523-530. doi:10.1080/00032717308058700
[16] J. Glastrup, "Diazomethane Preparation for Gas Chromatographic Analysis," Journal of Chromatography A, Vol. 827, No. 1, 1998, pp. 133-136. doi:10.1016/S0021-9673(98)00745-6

[17] C. J. Hardy and D. Scargill, "Studies on Mono- and Di-n-Butylphosphoric Acids. II the Solubility and Distribution of Mono- and Di-n-Butylphosphoric Acids in Aqueous-Organic Solvent Systems," Journal of Inorganic and Nuclear Chemistry, Vol. 11, No. 2, 1959, pp. 128143. doi:10.1016/0022-1902(59)80057-9

[18] P. Velavendan, S. Ganesh, N. K. Pandey, U. Kamachi Mudali and R. Natarajan, "Gas Chromatographic Determination of Di-n-Butyl Phosphate in Radioactive Lean Organic Solvent of FBTR Carbide Fuel Reprocessing," Nuclear and Radiochemistry Symposium, Visakhapatnam, Vol. 1, 22-26 February 2011, pp. 250-251.

[19] P. Velavendan, N. K. Pandey, U. K. Mudali and R. Natarajan, "Ion Chromatographic Determination of Di-n-Butyl Phosphate in Degraded Organic Solvent," Nuclear and Radiochemistry Symposium, Visakhapatnam, Vol. 1, 22-26 February 2011, pp. 234-235. 